\title{
Elevated temperatures drive the evolution of armor loss in the threespine
}

\section{2 stickleback Gasterosteus aculeatus}

4 Carl SMITH ${ }^{1,2,3 *}$, Grzegorz ZIĘBA ${ }^{1}$ and Mirosław PRZYBYLSKI ${ }^{1}$

3Institute of Vertebrate Biology, Czech Academy of Sciences, Květná 8, 60365 Brno, Czech Republic;

* Corresponding Author: Carl Smith, carl.smith@biol.uni.lodz.pl

Abstract. While there is evidence of genetic and phenotypic responses to climate change, few studies

have demonstrated change in functional traits with a known genetic basis. Here we present evidence

for an evolutionary adaptive response to elevated temperatures in freshwater populations of the

threespine stickleback (Gasterosteus aculeatus). Using a unique set of historical data and museum

a population-level decline in the number of lateral bony plates, comprising anti-predator armor, in

elevated temperatures and is proposed to be a correlated response to selection for reduced body size.

This study demonstrates a change in a functional trait of known genetic basis in response to elevated

temperature, and illustrates the utility of the threespine stickleback as a model for measuring the 


\section{Introduction}

25 The central assumption of evolutionary theory is that natural selection drives phenotypic adaptation

of populations to local environmental conditions through changes in the genetic composition of the

population. These adaptive changes arise from the differential reproductive success of individuals

that vary genetically (Darwin 1859; Fisher 1930; Williams 1966). In this context, the capacity of natural

populations to respond to rapid climate change is contingent on adaptive change to phenotypic traits

that have a genetic basis. While numerous studies demonstrate correlations between temperature and

phenotypic traits, many traits are highly plastic and the adaptive value of these changes is unclear

To unequivocally show an adaptive evolutionary response to climate change it is necessary to

demonstrate consistent and predicted alteration in a functional trait that is under genetic control. A

suitable species is one with short generation time, subject to high or consistent selection pressure for

a trait under simple genetic control and with standing genetic variation present in populations

(Crozier \& Hutchings 2014). The threespine stickleback (Gasterosteus aculeatus) is a model vertebrate

in behavioral and evolutionary biology that possesses these features and is widely distributed across

the northern hemisphere. The species occupies a wide range of environments and shows a high 
in concert, with anterior lateral plates bracing the dorsal and pelvic spines, which thereby resist

compression while also limiting ingestion by gape-limited vertebrate predators (Reimchen, 1994).

Marine sticklebacks are almost exclusively represented by a complete ecomorph, with $>30$ lateral plates

along the entire body. Posterior lateral plates appear to function in preventing skin puncture by

variable number of lateral plates, and is typically encountered in brackish water (Wootton, 1976).

Population-level change in the number of lateral plates can be rapid, with a reversal in plate ecomorph

dominance in as few as 10 generations (e.g. Bell et al., 2004; Kitano et al., 2008).

The accepted contemporary model for threespine stickleback lateral plate evolution involves

the repeated, independent establishment of freshwater populations from ancestral, panmictic

populations of fully-plated marine fish. Multiple genomic regions have been associated with

adaptation to fresh water (Jones et al., 2012), with the ectodysplasin A (EDA) locus specifically

with variation in EDA (Cresko et al., 2004; Colosimo et al., 2005). Marine populations are assumed to

possess a pool of standing genetic variation, with rare variants of the EDA locus experiencing strong

selection once fish enter fresh water, where they rapidly increase in frequency (Barrett, 2010).

A number of hypotheses have been proposed to explain the selective agent responsible for

armor loss in freshwaters, including predation, calcium and phosphorus availability, water density,

2009; Barrett, 2010; Smith et al. 2020b). At a large geographic scale, it is also apparent that temperature 
waters in eastern Europe and the east coast of North America, where they are associated with low winter temperatures (Wootton, 1976, 2009; Hagen \& Moodie, 1982). The almost ubiquitous occurrence of complete ecomorph populations in Poland, in particular, has been the focus of research for many decades (e.g. Piesik 1937; Penczak 1965; Bańbura 1989; Smith et al. 2020b).

lateral plate number provides an opportunity to investigate whether large-scale climate trends can

distribution, tolerance of a wide range of environmental conditions, and striking phenotypic underpinning climate change. sticklebacks over the past nine decades, corresponding with increasing environmental temperatures,

\section{Material and Methods}

Fish data

90 Samples of threespine sticklebacks were collected in 2017 and 2018 from 61 sites across Poland using 91 electrofishing, dipnets and small Seine nets. Collected fish were killed with anesthetic (benzocaine) 92 and fixed in $4 \%$ buffered formalin. For each fish, a record was made of standard length (SL, measured 93 from the tip of the snout to the origin of the tail) and total number of lateral plates on the left flank of

94 the body. An additional 15 samples were obtained from the archive of the Museum of the Institute of 95 Zoology of the Polish Academy of Sciences in Warsaw. These samples were collected between 1927 
and 1963. Specimens were measured for SL and the total number of lateral plates on the left side of

each fish counted. Information on the date and location of collected specimens were available. Finally,

we used previously published data from colleagues at the University of Łódź (Penczak 1960, 1962;

Bańbura 1988, 1994), that included fish collections conducted between 1947 and 1987 for 78

populations. Thus, data were obtained for 154 Polish populations spanning 91 years (1927-2018). The

locations of sampling sites are illustrated in Fig. 1. and summarized in Table S1. Samples were restricted to adult fish >27 mm SL to ensure lateral plate development was complete (Bańbura 1989).

Temperature data

105 Temperature data were compiled from 34 meteorological stations across Poland. Daily air temperature data were available from January 1881 until the present, though not for all weather stations. For each stickleback collection site, the mean of the 10-year antecedent air temperatures $\left(\mathrm{T}_{10}\right)$ from the geographically nearest weather station with a complete time series of data was calculated for each stickleback sampling location. A period of 10 years was used because this is sufficient time change (Bell et al. 2004). For some sample locations, a complete 10-year time-series of temperature data was not available (data collection was interrupted at some locations during WWII and in its immediate aftermath), in which case an incomplete time series was used. The spatial distribution of weather station are summarized in Tables S1 and S2.

Data analysis

118 Data were modelled using R (version 4.0.2; R Development Core Team 2020) with models fitted in a 119 Bayesian framework using INLA (Integrated Nested Laplace Approximation) with the R-INLA 
package (Rue et al. 2017). To model the data at the population level, lateral plate count (Gaussian

121 distribution) was regressed against historical temperature data and body size. Data exploration

122 suggested trends in plate number associated with changes in the 10-year antecedent near-surface air

123 temperature (SAT) anomaly over the last nine decades (Fig. 2A), particularly associated with a rapid

124 rise in the European SAT over the last three decades (Fig. 2B). These data included spatial patterns

125 arising from variation in sample locations through time, in combination with spatial variation in SAT

126 among sample locations, resulting in residual spatial autocorrelation (Legendre 1993). To

127 accommodate this potentially confounding structure to the data, we used spatially explicit, Bayesian

128 approximation methods to generate model parameter estimates. R-INLA includes functions to

129 construct Gaussian Markovian random fields (GMRFs) that permit parameter estimation in relation

130 to spatial structure in the data (Lindgren et al., 2011). GMRFs are estimated using Matérn correlation

131 solved with a stochastic partial differential equation (SPDE) on a 'mesh', comprising small, non-

132 overlapping triangles that encompass the sampling area (Zuur et al. 2017). Using this approach, we

133 modeled threespine stickleback plate number as a function of body size (SL) and $\mathrm{T}_{10}$ from the

134 geographically nearest weather station to each sampling site, while accommodating spatial

135 dependency in the data. We predicted a negative relationship between plate number and $\mathrm{T}_{10}$ and a

136 positive relationship with body size (Smith et al. 2020b).

Seven models were fitted to the data, with SL and T10 either included or removed, and with or

without the inclusion of a spatially correlated random effect. A baseline model was also included,

comprising an intercept and spatially correlated random effect only. Model selection was conducted

$$
\text { Plate }_{i} \sim N\left(\mu_{i}, \sigma^{2}\right)
$$


Where Plate i is the number of lateral plates for the stickleback population at sampling location $i$

assuming a Gaussian distribution with mean $\mu_{i}$ and variance $\sigma^{2}$. The variable $S L_{i}$ is a continuous

covariate representing population standard length at sampling location $i$, and Temperature $i$ is a

continuous covariate representing the mean 10-year antecedent air temperature at location $i$. The term

$u_{i}$ is a spatially correlated random effect at sampling location $i$ with mean 0 and covariance $\Sigma$.

\section{Results}

In the best-fitting model, both body size and $\mathrm{T}_{10}$ were statistically important predictors of lateral plate number (Table 2, Fig 4A-C). As predicted, $\mathrm{T}_{10}$ showed a negative association with lateral plate number (Fig. 5A), while body size showed a positive association (Fig. 5B). Approximately 27\% of the variation in lateral plate number was explained in the spatial random field and the GMRF indicated the strongest negative effects on plate number in the north-west and north-east of Poland and positive effects in central Poland. These locations also showed elevated variance of the GMRF 
(Fig. 3C). Spatial dependency in lateral plate number was important at a scale of $3.6 \mathrm{~km}$ (Table 2, Fig.

4D).

\section{Discussion}

172 Using a latent Gaussian model, we provide evidence that over multiple decades, and on a large spatial

173 scale, variation in threespine stickleback lateral plate number is predicted by antecedent air 174 temperature. This effect is mediated by body size; elevated temperatures select for reduced body size 175 in the threespine stickleback, which is negatively correlated with plate number (Fig. 5; Smith et al. 176 2020b). Strong negative effects of the GMRF on plate number were observed in the north-west and 177 north-east of Poland (Fig. 3B), with both locations also showing elevated variance (Fig. 3C). In the 178 north-west of Poland, the River Oder debouches into the Szczecin Lagoon and the Baltic Sea, 179 permitting heavily-plated complete ecomorph threespine sticklebacks to penetrate freshwater systems 180 from the Baltic. In the north-east of the area for which data were available (now in south-east 181 Lithuania) minimum winter temperatures are extremely low for the region, sometimes falling below $-30{ }^{\circ} \mathrm{C}$. Thus, these effects are proposed as being a function of large-bodied and heavily-armored sticklebacks penetrating inland through a large river and lagoon system, in combination with selection for large body size in a region of unusually low environmental temperatures. Strong positive effects of the GMRF were also observed in Central Poland. In this region, plate numbers are depressed

(Fig. 3B) and with low variance (Fig. 3C). This pattern may reflect local thermal pollution associated with the discharge of heated waste water from large cities, such as Warsaw and Łódź (Kalinowska et al., 2012).

The findings of this study are significant in demonstrating that temporal change in temperature can drive rapid natural adaptation in a phenotypic trait with a known genetic basis. 
plastic traits, such as fecundity, survival, timing of migration and reproductive phenology (Crozier and Hutchings 2014). Growth is also a plastic trait in the threespine stickleback (e.g. Mccairns and and number (Hansson et al. 2016) are not. The effect demonstrated here represents a rare example of

the result does not simply represent variance in phenotype along a spatial climatic gradient, which can be a reflection of adaptation to contrasting environmental conditions. Instead, after controlling for spatial patterns in the data, we show a broad trend of declining plate number in response to a long-term increase in environmental temperature.

An association between threespine stickleback lateral plate number and temperature has been recognized for several decades, though it has never been adequately explained (Heuts, 1947; Hagen

\& Moodie, 1982; Wootton, 2009). High numbers of lateral plates are particularly characteristic of fresh water populations exposed to low winter temperatures on the eastern and northern fringes of continents (Wootton, 1976; Hagen \& Moodie, 1982). In contrast, low numbers of lateral plates are associated with mild winter temperatures in the south and west of the geographic range of the species (Wootton 2009; Smith et al. 2020b). Despite this striking pattern, the association between plate number and temperature has not been a feature of discussions on other potential selective agents for the evolution of plate number in the threespine stickleback, at least until recently (Des Roches et al. 2019; Smith et al. 2020b).

It is unclear whether reduced plate number represents an adaptive response to elevated 212 temperatures or a correlated response to selection for reduced body size. If a reduction in plate number is mediated by a change in body size, as proposed here, there may be no adaptive advantage to fewer lateral plates at elevated temperatures. Reduced body size as a response to higher 
216 Bergmann's rule is unclear but applies across a range of endotherms and ectotherms, including fishes

217 (Belk \& Houston, 2002). In the case of ectotherms, higher resting metabolic rates may incur higher

218 energetic costs that compromise growth. Selection for large offspring body size at low temperatures

219 may also play a role (Pettersen et al., 2019).

An implication of a correlated response between body size and lateral plate number is that

221 variation in lateral plate number has no Darwinian adaptive advantage and solely reflects a scaling

222 relationship sensu Thompson (1917). Alternatively, natural selection may drive changes in body size

223 in response to temperature, with plate number varying to optimize mechanical efficiency at a given

224 body size (Bonner \& Horn, 2000). In aquatic animals scaling effects have particular consequences for

225 hydrodynamic resistance to movement (Schmidt-Nielsen, 1984). Lateral plates increase drag in the

226 threespine stickleback and correlate negatively with swimming velocity after correcting for body size

227 (Bergstrom, 2002). An outcome is that selection on sticklebacks for armor loss will minimize drag

228 (Walker, 1997; Bergstrom, 2002), and sticklebacks that experience selection for reduced body size at

229 elevated temperatures are predicted to simultaneously experience selection for plate loss to avoid

230 compromising hydrodynamic efficiency (Smith et al., 2020b).

The threespine stickleback is common and widespread species across coastal regions of the

northern hemisphere (Wootton 1976). It is a vertebrate model in evolutionary, genomic, behavioral and ecological studies, and has been the subject of a broad range of research questions for over a

historical data sets and archived samples, and potentially also in the fossil record (Bell 2009). This

evolutionary and ecological impacts of climate change across the northern hemisphere. 


\section{Acknowledgements}

241 We are grateful to Jerzy Bańbura, Martin Reichard and Rowena Spence for comments. Research was

242 supported by the POLONEZ Fellowship of National Science Centre, Poland (2015/19/P/NZ8/03582).

243 This project has received funding from the European Union's Horizon 2020 research and innovation

244 program under the Marie Skłodowska-Curie grant agreement No. 665778. 


\section{References}

Bańbura, J. (1988). Różnorodność fenotypowa ciernika, Gasterosteus aculeatus L. w wodach Polski. $\mathrm{PhD}$ thesis, University of Łódź, Poland.

Bańbura, J. (1989). Lateral plate number development in the complete morph of the three-spined stickleback, Gasterosteus aculeatus L. Zool. Script. 18, 157-159.

Bańbura, J., 1994. Lateral plate morph differentiation of freshwater and marine populations of the three-spined stickleback, Gasterosteus aculeatus, in Poland. J. Fish Biol. 44, 773-783.

Barrett, R.D.H. (2010). Adaptive evolution of lateral plates in three-spined stickleback Gasterosteus aculeatus: a case study in functional analysis of natural variation. J. Fish Biol. 77, 311-328.

Barrett, R.D., Rogers, S.M. and Schluter, D., 2008. Natural selection on a major armor gene in threespine stickleback. Science 322, 255-257.

Belk, M.C. \& Houston, D.D. (2002). Bergmann's rule in ectotherms: A test using freshwater fishes. Am. Nat. 160, 803-808.

Bell, M.A., 2009. Implications of a fossil stickleback assemblage for Darwinian gradualism. J. Fish Biol. 75, 1977-1999.

Bell, M.A., Aguirre, W.E. \& Buck, N.J. (2004). Twelve years of contemporary armor evolution in a threespine stickleback population. Evolution 58, 814-824.

Bell, M.A. \& Foster, S.A. (1994). Introduction to the evolutionary biology of the threespine stickleback. In The evolutionary biology of the threespine stickleback: 1-27. Bell, M.A. \& Foster, S.A. (Ed.). Oxford University Press.

Bergmann, C. (1847). Über die verhaltnisse der warmeokonomie de thiere zu ihrer gross. Göttinger Studien 1, 595-708.

Bergstrom, C.A. (2002). Fast-start swimming performance and reduction in lateral plate number in threespine stickleback. Can. J. Zool. 80, 207-213.

Bonner, J.T. \& Horn, H.S. (2000). Allometry and natural selection. In Scaling in biology: 1-24. Brown, J.H. \& West, G.B. (Ed.). Oxford University Press.

Colosimo, P.F., Hosemann, K.E., Balabhadra, S., Villarreal, G., Dickson, M., Grimwood, J. Schmutz, J., Myers, R.M., Schluter, D. \& Kingsley, D.M. (2005). Widespread parallel evolution in sticklebacks by repeated fixation of ectodysplasin alleles. Science 307, 1928-1933.

Cresko, W.A., Amores, A., Wilson, C., Murphy, J., Currey, M., Phillips, P., Bell, M.A., Kimmel, C.B. \& Postlethwait, J.H. (2004). Parallel genetic basis for repeated evolution of armor loss in Alaskan threespine stickleback populations. Proc. Nat. Acad. Sci. 101, 6050-6055.

Crozier, L.G. and Hutchings, J.A., 2014. Plastic and evolutionary responses to climate change in fish. Evol. Appl. 7, 68-87.

Darwin, C. 1859. On the origin of species by means of natural selection, or the preservation of favoured races in the struggle for life. John Murray, London. 
Des Roches, S., Bell, M.A. \& Palkovacs, E.P. (2019). Climate-driven habitat change causes evolution in threespine stickleback. Glob. Change Biol. 26, 597-606

Fisher, R.A. 1930. The genetical theory of natural selection. The Clarendon Press, Oxford.

Hagen, D.W. \& Moodie, G.E.E. (1982). Polymorphism for plate morphs in Gasterosteus aculeatus on the east coast of Canada and an hypothesis for their global distribution. Can. J. Zool. 60, 10321042.

Hansson, T.H., Fischer, B., Mazzarella, A.B., Voje, K.L. and Vøllestad, L.A., 2016. Lateral plate number in low-plated threespine stickleback: a study of plasticity and heritability. Ecol. Evol. 6, 3154-3160.

Heuts, M.J. (1947). Experimental studies on adaptive evolution in Gasterosteus aculeatus L. Evolution $1,89-102$.

Jones, F.C., Grabherr, M.G., Chan, Y.F., Russell, P., Mauceli, E., Johnson, J., Swofford, R., Pirun, M., Zody, M.C., White, S. \& Birney, E. (2012). The genomic basis of adaptive evolution in threespine sticklebacks. Nature 484, 55.

Kalinowska, M.B., Rowiński, P.M., Kubrak, J. \& Mirosław-Świątek, D. (2012). Scenarios of the spread of a waste heat discharge in a river-Vistula River case study. Acta Geophysica 60, 214231.

Kitano, J., Bolnick, D.I., Beauchamp, D.A., Mazur, M.M., Mori, S., Nakano, T. \& Peichel, C.L. (2008). Reverse evolution of armor plates in the threespine stickleback. Curr. Biol. 18, 769-774.

Legendre, P., 1993. Spatial autocorrelation: trouble or new paradigm? Ecology 74, 1659-1673.

Lindgren, F., Rue, H. and Lindström, J., 2011. An explicit link between Gaussian fields and Gaussian Markov random fields: the stochastic partial differential equation approach. J. R. Stat. Soc. B 73, 423-498.

Marchinko, K.B., 2009. Mechanisms of divergence in threespine stickleback (Gasterosteus aculeatus) PhD thesis, University of British Columbia, Canada.

Mccairns, R.S. and Bernatchez, L., 2012. Plasticity and heritability of morphological variation within and between parapatric stickleback demes. J. Evol. Biol. 25, 1097-1112.

Münzing, J. (1963). The evolution of variation and distributional patterns in European populations of the three-spined stickleback, Gasterosteus aculeatus. Evolution 17, 320-332.

Myhre, F. and Klepaker, T., 2009. Body armour and lateral-plate reduction in freshwater threespined stickleback Gasterosteus aculeatus: adaptations to a different buoyancy regime? J. Fish Biol. 75, 2062-2074.

Penczak, T., 1960. Studies on the stickleback (Gasterosteus aculeatus L.) in Poland. Part I. Fragm. Faun., Warsaw 8, 367-400.

Penczak, T., 1962. The biometry of the threespine stickleback Gasterosteus aculeatus L. from the Ner River. Fragm. Faun., Warsaw 10, 137-161. 
Penczak, T., 1965. Morphological variation of the stickleback (Gasterosteus aculeatus L.) in Poland. Zool. Polon. 15, 3-49.

Pettersen, A.K., White, C.R., Bryson-Richardson, R.J. \& Marshall, D.J. (2019). Linking life-history theory and metabolic theory explains the offspring size-temperature relationship. Ecol. Lett. 22, $518-526$.

Piesik, J. 1937. Three-spined stickleback. Czasop. Przyr. Ilustr., Lodz. 11, 117-129

R Development Core Team (2020). R: A language and environment for statistical computing. Vienna: $\mathrm{R}$ Foundation for Statistical Computing.

Reimchen, T.E. 1994. Predators and evolution in threespine stickleback. In The evolutionary biology of the threespine stickleback: 240-273. Bell, M.A. \& Foster, S.A. (Ed.). Oxford University Press.

Roos, M. and Held, L., 2011. Sensitivity analysis in Bayesian generalized linear mixed models for binary data. Bayesian Anal. 6, 259-278.

Rue, H., Riebler, A., Sørbye, S.H., Illian, J.B., Simpson, D.P. \& Lindgren, F.K. (2017). Bayesian computing with INLA: a review. Ann. Rev. Stat. Appl. 4, 395-421.

Smith, C., Zięba, G., Spence, R., Klepaker, T. and Przybylski, M., 2020b. Three-spined stickleback armour predicted by body size, minimum winter temperature and pH. J. Zool. 311, 13-22.

Smith, C., Zięba, G., Spence, R. and Przybylski, M., 2020a. New finding of melanic three-spined sticklebacks Gasterosteus aculeatus in the Scottish Hebrides. J. Vertebr. Biol. 69: 20039.

Spiegelhalter, D.J., Best, N.G., Carlin, B.P. and Van Der Linde, A., 2002. Bayesian measures of model complexity and fit. J. R. Stat. Soc. B Methods 64, 583-639.

Thompson, D.W. (1917). On growth and form. Cambridge University Press.

Walker, J.A. (1997). Ecological morphology of lacustrine threespine stickleback Gasterosteus aculeatus L. (Gasterosteidae) body shape. Biol. J. Linn. Soc. 61, 3-50.

Williams, G.C. 1966. Adaptation and natural selection. Princeton University Press.

Wootton, R.J. (1976). Biology of the sticklebacks. London: Academic Press.

Wootton, R.J. (1984). A functional biology of sticklebacks. London: Croom Helm.

Wootton, R.J. (2009). The Darwinian stickleback Gasterosteus aculeatus: a history of evolutionary studies. J. Fish Biol. 75, 1919-1942.

Zuur, A.F., Ieno, E.N. and Saveliev, A.A., 2017. Spatial, temporal and spatial-temporal ecological data analysis with R-INLA. Highland Statistics Ltd, Newburgh. 


\section{9}

350

351

352

353

\section{Figure Legends}

Fig. 1. Collection sites of threespine stickleback samples (red dots) and weather stations (blue dots) in Poland. Note that one sample, in the top right of the figure, falls outside the current Polish border. When this sample was collected (September 1928) the collection site was on Polish territory (now in Lithuania).

Fig. 2. (A) Bubble plot of threespine stickleback lateral plate number against standard length (mm), with size of points relative to mean 10-year antecedent near-surface air temperature (SAT) anomalies over land for Europe $\left({ }^{\circ} \mathrm{C}\right)$ from the CRUTEM4 dataset compiled by the UK Met Office Hadley Centre (www.metoffice.gov.uk/hadobs/ hadcrut4). Different colored points represent different decades; (B) Plot of 10-year antecedent SAT anomalies over land for Europe $\left({ }^{\circ} \mathrm{C}\right)$ from the CRUTEM4 dataset by year from 1927 - 2018, the period over which threespine stickleback data were collected and compiled. The black line is the mean SAT and shaded area is the 95\% confidence interval.

Fig. 3. (A) Mesh of 3,874 vertices generated by constrained refined Delaunay triangulation; (B) Posterior mean values of the GMRF estimated for threespine stickleback plate number across Poland; (C) Variation (SD) of the GMRF estimated for threespine stickleback plate number.

Fig. 4. Posterior (marginal) distributions for: (A) model intercept; (B) standard length; (C) average 10year antecedent air temperature; (D) Matérn correlation function.

Fig. 5. Posterior mean fitted estimates of lateral plate number for threespine sticklebacks as a function of: (A) average 10-year antecedent air temperature; (B) population standard length (mm). Shaded areas are $95 \%$ credible intervals. Black points are observed data for stickleback populations. 
Figure 1

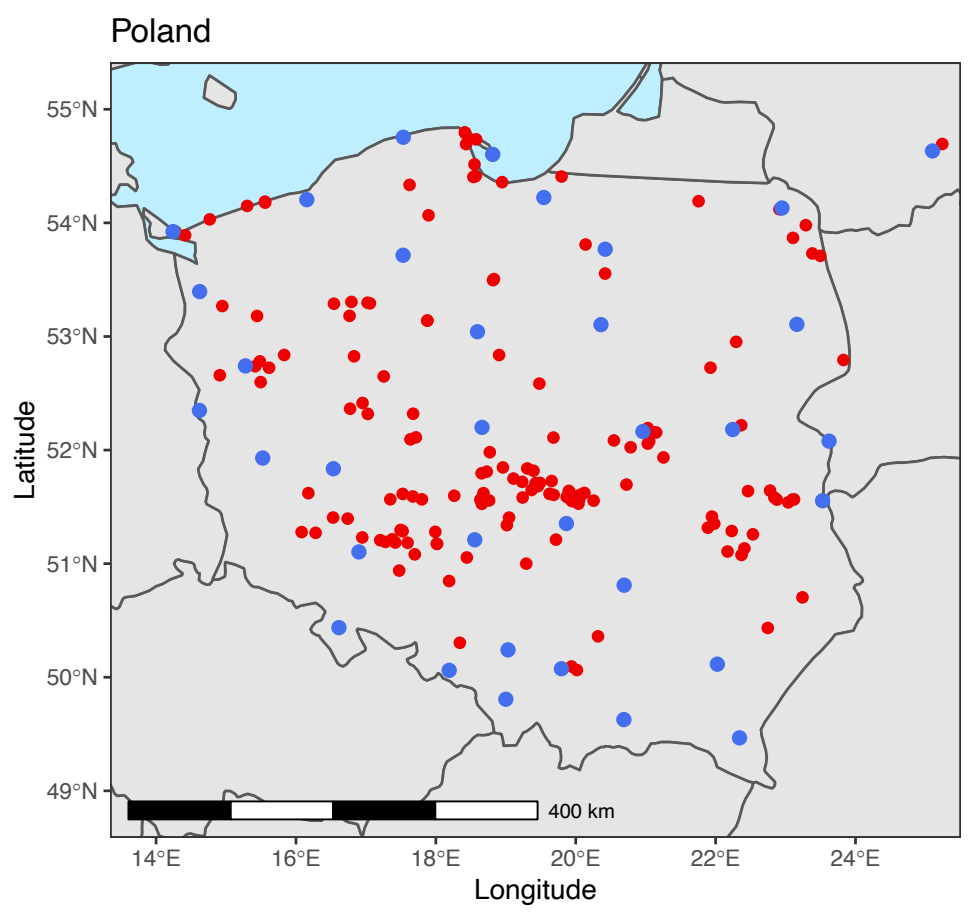


Figure 2
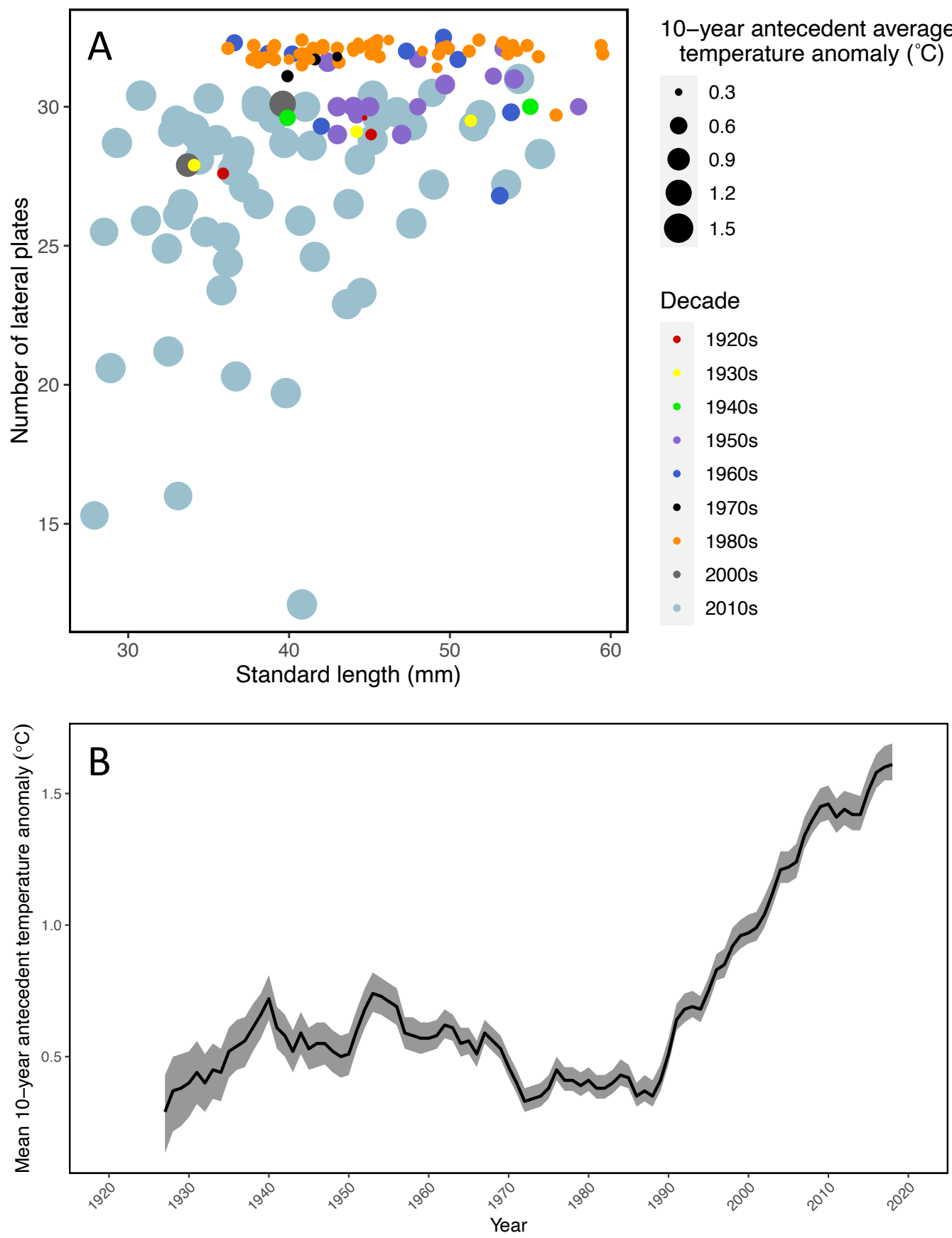
Figure 3
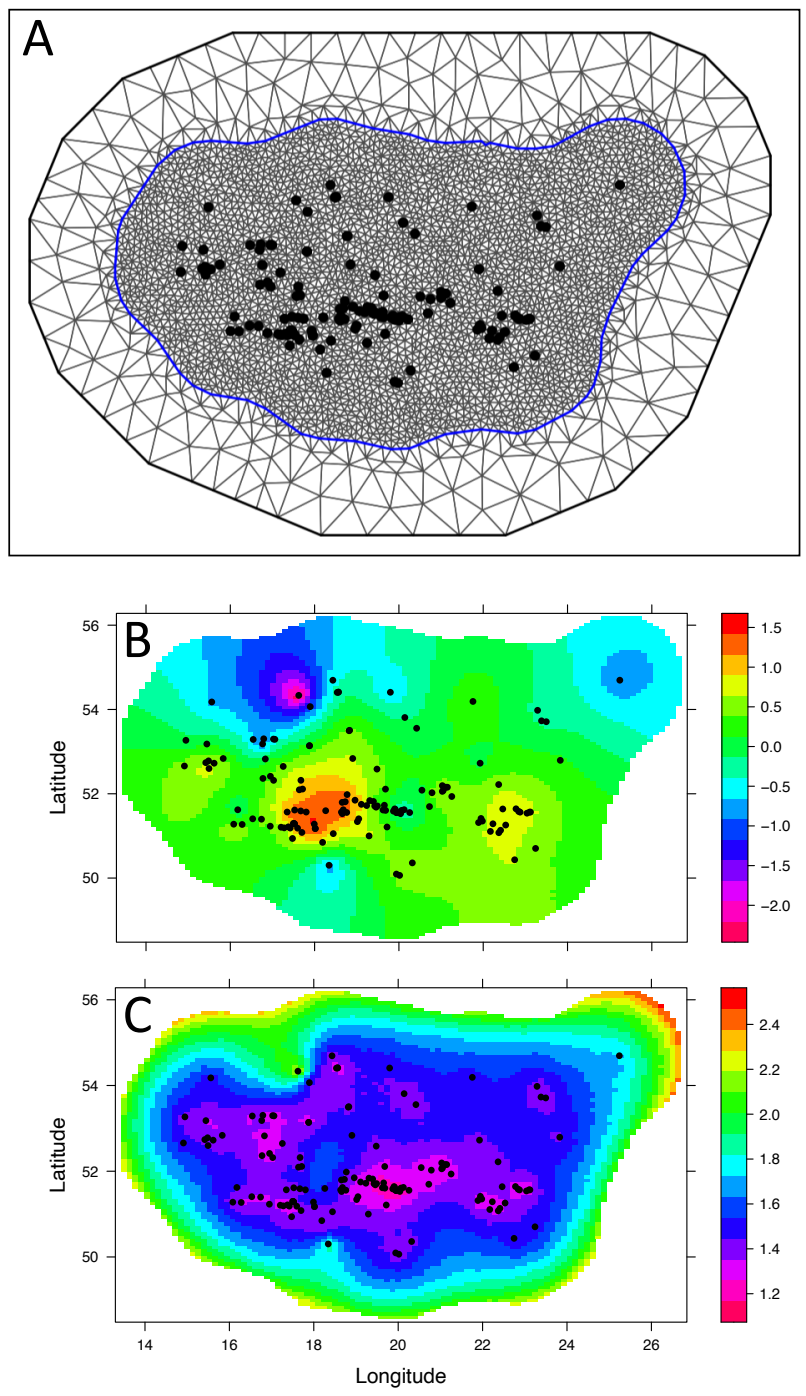

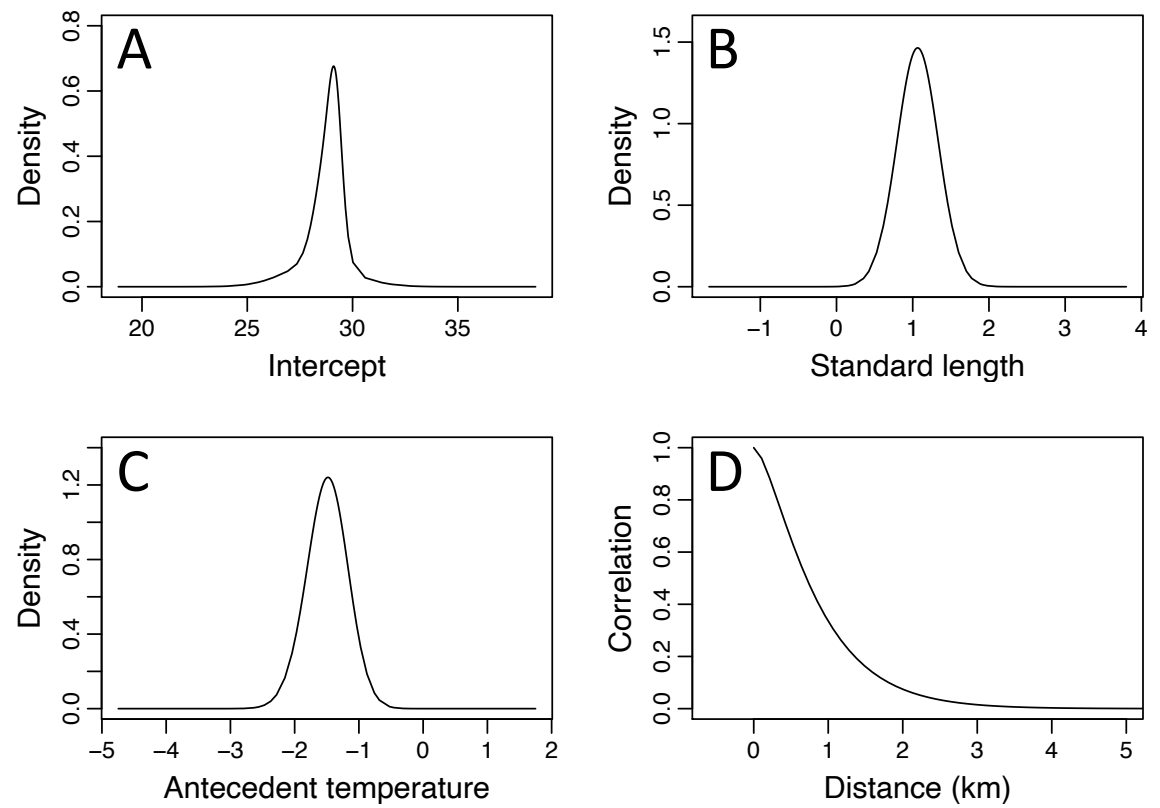
Figure 5
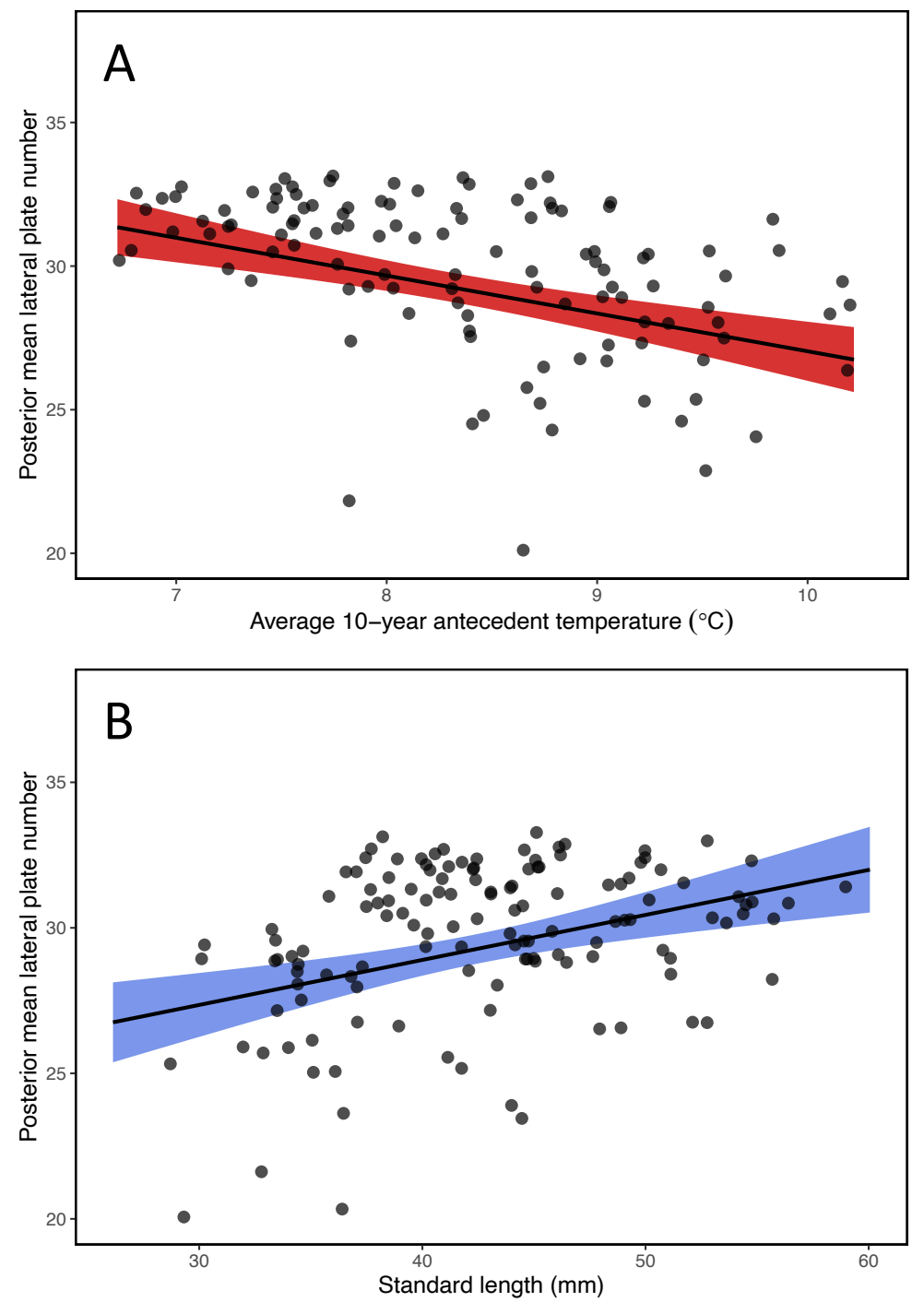
Table 1. Deviance Information Criterion (DIC) and Log-Conditional Predictive Ordinates (LCPO) of fitted models using Integrated Nested Laplace Approximation (INLA) to determine threespine stickleback lateral plate number. SL is stickleback standard length, $\mathrm{T}_{10}$ is the average 10-year antecedent air temperature. Models ranked by DIC and LCPO.

\begin{tabular}{clcc}
\hline Rank & Model & DIC & LCPO \\
\hline 1 & Spatial effect + SL + T10 & 693 & 350 \\
2 & SL + T10 & 698 & 351 \\
3 & Spatial effect + T10 & 705 & 357 \\
4 & T10 & 711 & 358 \\
5 & Spatial effect + SL & 715 & 359 \\
6 & SL & 719 & 361 \\
7 & Spatial effect only & 739 & 371 \\
\hline
\end{tabular}


bioRxiv preprint doi: https://doi.org/10.1101/2020.10.29.361568; this version posted October 30, 2020. The copyright holder for this preprint (which was not certified by peer review) is the author/funder, who has granted bioRxiv a license to display the preprint in perpetuity. It is made available under aCC-BY-NC-ND 4.0 International license.

Table 2. Fixed effects from the best-fitting model for threespine stickleback lateral plate number in Poland. Credible intervals are the $2.5 \%$ and $97.5 \%$ quantiles. Hyperparameters are: $\kappa_{\text {spatial }}=1.78, \sigma_{\text {spatial }}=1.31 ;$ range $=3.56 \mathrm{~km}$. Credible intervals that do not include zero indicate statistical importance.

\begin{tabular}{lccc}
\hline Term & Posterior mean & $2.5 \%$ quantile & 97.5\% quantile \\
\hline Intercept & 28.77 & 26.17 & 30.63 \\
Standard length (SL) & 1.07 & 0.53 & 1.60 \\
10-year antecedent temperature ( $\left.\mathrm{T}_{10}\right)$ & -1.50 & -2.15 & -0.88 \\
\hline
\end{tabular}

